\title{
Theory on the Functions of A Firm: A Resolution to Smith's Dilemma
}

\author{
Zhong-Yuan Han \\ Antai College of Economics\&Management \\ Shanghai Jiaotong University \\ No.1954-26\#,Hua Shan Rd. Shanghai. China 200030 \\ E-mail: hanzhongyuan@yeah.net
}

Shu-Lin Wang (Corresponding Author)

Sun Wah International Business School, Liaoning University

No.58 JingShen Street, Daoyi District, Shenyang

Liaoning Province, China, 110034

Tel: +86-24-6260-2051_E-mail:wangjlgsh@hotmail.com

Received: September 6, 2010

doi:10.5430/jms.v3n1p18
Accepted: February 1, 2012 Published: February 15, 2012

URL: http://dx.doi.org/10.5430/jms.v3n1p18

\begin{abstract}
Based on Stigler's (1951) conjecture, this article reproves the Smith theorem (the division of labor is limited by the extent of the market), via a framework of perfect competitive market, consequently offering a solution to Smith's dilemma which usually refers to the incompatibility between the Smith theorem and the theory of competitive price.
\end{abstract}

Keywords: Smith's dilemma, Functions of the firm, Division of labor, Extent of the market

\section{Introduction}

The Smith dilemma refers to the incompatibility between the Smith theorem (the division of labor is limited by the extent of market) and the theory of competitive price. Stigler (1951) and Heal (1999) have mentioned that due to this incompatibility, we face hard decision to use either theory. On one hand, according to Smith's theorem, market growth prompts further division of labor and specialization, giving rise to increasing returns to scale. Consequently, the firm's average cost will fall as the quantity of the output increases and its marginal cost curve is beneath the average cost curve. On the other hand, from the theory of competitive price, we know firm is the price taker and the supply curve is its marginal cost curve above the minimum average cost in the long-run. When the market price is less than the firm's minimum average cost, the firm will shutdown. With increasing returns, the firm's marginal cost curve is beneath the average cost curve, and we can't develop a stable equilibrium, which means that we cannot use the price mechanism to allocate the resources in a competitive market anymore. What's more, we can also try to understand this incompatibility from other aspects. When the market price is high enough, a firm with increasing returns will enlarge its profit by increasing the output. Eventually, perfect competition cannot be sustained, which also illustrate the incompatibility between increasing returns to scale and perfect competition. As Stigler (1951) said,

"And here was the dilemma: either the division of labor is limited by the extent of market, and, characteristically, industries are monopolized; or industries are characteristically competitive, and the Theorem is false or of little significance. There were and are plenty of important competitive industries; yet Smith's argument that Highlanders would be more efficient if each did not have to do his own baking and brewing also seems convincing and capable of wide generalization."

After Adam Smith, many his successors have attempted to solve this dilemma, such as Ricardo (1817), Senior (1836), J. S. Mill (1948), Marshall (1920) and Allyn Young (1928). However, none of them have really provided a solution to it. Stigler (1951) proposes the theory of the functions of a firm which presents us a feasible approach to incorporate the Smith Theorem into competitive price theory. He argues that firms consist of different functional sectors and each sector 
is with different cost structures from the others. Particularly, one sector may decrease its cost as the production expands while another is with increasing cost. When the extent of market is too small to support the functional sector with increasing returns departing from its firm and specializing its production, all sectors will produce within an integrated firm. However, with the increase of market demand, the functional sector with increasing returns would be spun off and become a newly independent supplier of the original firm to specialize its production (Note 1). The price charged by the newly specialized firm will not be higher than the average cost of intermediate goods produced by the functional sector with increasing returns prior to the disintegration, otherwise, the original firm would not accept it and prefer to producing by itself. At first there would be monopoly in the new specialized industry, but with continued market growth, more new specialized firm will enter, eventually, leading to more competition.

Perry (1989) questions the way Stigler defines "the specialization" and argues that besides economies of scale, specialization would also mean diseconomies of scope across vertically related production sectors. Another issue is that Stigler doesn't point out the exact nature of the free entry equilibrium in the newly specialized industry, i.e. the price and number of firms (Note 2).

Upon the arguments on Stigler's proposition, we find the main reason is that Stigler doesn't state a formal model. Indeed, many authors try to model and empirically test Stigler's idea. Perry and Groff (1988) have proposed a theoretical model for Stigler's (1951) studies via a framework of imperfect competition at the upstream industry, and found that when the number of firms increases proportionally with the number of consumers, we can see the case of vertical disintegration. There are three conceptual problems in their model. First, it does not show us the number of the endogenous upstream firms. Meanwhile, since the model is proved under the assumption of imperfect competition, it does not solve the Smith's dilemma. Another paradox of the model pointed by Dufeu (2004) is the conflict between exclusion of partial vertical integration and the assumption that downstream firms do not have the fixed cost, since upstream firms have the incentives to produce small amount of the final goods with their own intermediate products while selling the rest of the intermediate goods to the downstream firms. Dufeu (2004) improves Perry and Groff's model, yet he still does not solve the first two potential problems of the model.

Based on Salinger's (1988) model, Elberfeld (2002) endogenizes the number of firms and confirms that market growth prompts vertical disintegration when market entry is free. However, the choice of specialization or integration does not depend on the different cost structures of the functional sectors within a firm, but the differences between the cost functions of integrated firms and that of the specialized ones. Obviously, Elberfeld (2002) has strayed from Stigler's (1951) thought, since he does not analyze the issue from the aspect of the functions of a firm, but focusing on the conditions for vertical integration and vertical disintegration.

Additionally, through distinguishing the general specialty from the localization specialty and comparing their cost differences in case of specialization, Bresnahan and Gambardella(1998)demonstrates that the extent of the market defined as the number of the downstream firms will lead to the rise of a vertically specialized firm producing general specialty. Similarly, Zhou (2004) specializes different types of production technologies, and assumes that more specialized technology is relatively subject to higher fixed cost and lower marginal cost, hence proving that specialization will increase with the market growth. However, they also deviate Stigler's proposition of the functions of a firm. In addition, giving Cournot oligopoly as the assumption, their model doesn't solve Smith's dilemma.

Locay's (1990) model of specialization is closer to represent Stigler's idea. However, since there's a conflict between his setting of average cost pricing and the principle of marginal cost pricing under the theory of competitive price, Smith's dilemma has not really been solved.

Regard Smith's dilemma, except Stigler's (1951) conjecture, there are some other lines of studies existing. For example, Dixit and Stiglitz (1977), within a monopolistic competition framework, develop the horizontal specialization (Note 3) equilibrium by optimizing the trade-off between scale economies and product diversity, hereby providing an approximation to Smith's dilemma (Ng and Zhang, 2003). Instead, Yang (1991), under the assumption of indivisible labor, develops the corner equilibrium by applying the infra-marginal analysis, hence circumventing the Smith dilemma (Note 4). Meanwhile, Baumgardner (1988), Becker and Murphy (1992), and etc also assume that labor is indivisible. Such kind of assumption will be helpful to analyze the individual professional specialization, but will lose its effectiveness to analyze the specialization and division of the labor on the firm and industry level. However, as Young (1928) and Stigler (1951) have clearly defined, the problem to be studied is the specialization and division of the labor of the firm and industry, which is also the distinction of our studies from Yang's (1991) (Note 5).

The core of Stigler's proposition is to prove Smith theorem in a framework of perfect competition, to apply Smith theorem to analyze the vertical integration and disintegration, and to view Smith theorem as a fundamental principle of industrial organization. One point we need to stress is that Smith theorem only illustrates the extent of the market as the 
necessary condition of the division of labor, but not the sufficient condition. When we analyze the issues of vertical integration and disintegration, we not only need to consider the extent of the market, but also need to take market structure, regulations and transaction costs into account (Note 6). Therefore, Smith theorem and vertical disintegration are two different issues, and shedding light on vertical disintegration does not mean to prove the Smith theorem. Yet if we can control the other factors that may influence vertical disintegration, like market structure, regulations, transaction costs and so on, focusing on the effect of the extent of market alone, then in the aspect of specialization and division of the labor of industry, explaining the issue of vertical disintegration is equivalent to resolving Smith theorem. Chen(2005)surveyed the vertical disintegration under a Cournot model. Many empirical studies also examined Smith theorem, like Arora et.al (2009) and Duranton \& Jayet(2011)and the vertical integration and disintegration, such as Nor et al(2006), Malerba et al(2008), Desyllas(2009), li\&Lu(2009) and so on..

Our article will follow the line of Stigler's (1951) study, setting up a theoretical model and solving the problems mentioned by Perry (1989), and try to provide a resolution to the Smith dilemma within a framework of perfect competition. We also admit that our model bears resemblance to Ciliberto \&Panzar(2011)'s model, however, in their model, the demand for the intermediate goods is exogenous, and their focus is not to solve Smith dilemma. Section 2 demonstrates the theoretical model and analyzes the conditions of vertical integration and disintegration. Section 3 summarizes and concludes the paper.

\section{The Model}

Using partial equilibrium approach, we assume the aggregate demand function for an industry is

$Q_{F}^{d}=Q_{F}^{d}(p, e), \frac{\partial Q_{F}^{d}}{\partial p}<0, \frac{\partial Q_{F}^{d}}{\partial e}>0$

where $p$ is the market price of the final goods and $e$ is the extent of the market. $\frac{\partial Q_{F}^{d}}{\partial p}<0$ means that the quantity

demanded will decrease as $p$ increases, namely, the aggregate demand curve slopes downwards. $\frac{\partial Q_{F}^{d}}{\partial e}>0$ means that keeping $p$ the same, quantity demanded will increase as $e$ increases. In other words, aggregate demand curve will shift up with an expansion of the extent of the market. Here, we define the extent of market as the aggregate demand for the industry, and take the aggregate demand curve to represent the extent of market. We also assume the extent of market is exogenous.

We assume that there are only two mechanisms allocating resources in this economy. One is the firm and the other is the competitive market (Note 7). Here we define the firm as one mechanism allocating resource via orders. That is to say, the firm will determine the quantity of inputs and outputs in different functional sectors via the orders. We define competitive market as the other resource allocation approach via prices. Individuals in the market are the price takers, enter the market with free, and satisfy the conditions of market clearing. Upon the decision to choose which mechanism to allocate resources, we assume, if we can use competitive market, we will not use firm to allocate the resources. In other words, only in case of failure via competitive market to allocate the resources can we turn to the firm. This failure refers that there's no such price to clear the market. According to Stigler (1951), a firm is composed of different functional sectors (upstream and downstream sectors) with different cost structures. Upstream sector of the firm produces intermediate good $q_{I}$ first, and then downstream sector of the firm produces final good $q_{F}$. Production functions for $q_{I}$ and $q_{F}$ are given by

$q_{F}=\min \left\{f\left(x_{F}\right), q_{I}\right\}$

$q_{I}=a f\left(x_{I}\right), a>1$

where $x_{I}$ is input $x$ needed to produce intermediate $\operatorname{good}_{q_{I}} ; x_{F}$ is the input $x$ needed to produce final good $q_{F}$. Within a perfect competitive market, we set the price of input $x$ as one. We also assume that $f(x)$ is a strictly quasi-concave function with $f^{\prime}(x)>0$. From the figure I, when $x<\hat{x}, f^{\prime \prime}(x)>0$; Otherwise, when $x>\hat{x}, f^{\prime \prime}(x)<0$. Let $f^{-1}(y) \equiv g(y)$. $a$ is the parameter representing the technical difference between two sectors, and $a>1$ means that different sectors hold different production technologies. The greater $a$ is, the more difference they have in their production technology. 
One discussion we concern is whether the intermediate good $q_{I}$ is allocated via the firm or the market. Therefore, firstly we will analyze the allocation taken within the firm, which is also the case of vertical integration, and then analyze the allocation via the market, which is the case of vertical disintegration. Finally, we can develop the conditions of vertical integration and vertical disintegration, hence proving the Smith theorem.

\subsection{Vertical integration}

A vertically integrated firm's cost-minimization problem is

$$
\min _{x_{1}, x_{2}} x_{F}+x_{I} \text { s.t.min }\left\{f\left(x_{F}\right), q_{I}\right\} \geq q_{F} .
$$

Solving for (4), we get the cost function of a vertically integrated firm as follows.

$$
C^{V I}\left(q_{F}\right)=x_{F}+x_{I}=g\left(q_{F}\right)+g\left(\frac{q_{F}}{a}\right)
$$

where the cost of the upstream sector producing immediate good is $C^{I}\left(q_{I}\right)=x_{I}=g\left(\frac{q_{I}}{a}\right)$ and the cost of the downstream sector producing final good is $C^{F}\left(q_{F}\right)=x_{F}=g\left(q_{F}\right)$.

From the Characteristics of $f(x)$ (see the proof in appendix), we know the average cost curves are all U-shaped for the integrated firm and its functional sectors, which can be seen in figure II, where $A C^{V I}$ represents the average cost of the vertically integrated firm, $A C^{I}$ is the average cost of the upstream sector and $A C^{F}$ is the average cost of the downstream sector.

In addition, when marginal cost equals the average cost, we get the minimum average cost. From figure II, we can see, $q_{I}^{* * *}$ is the optimum produced by the upstream sector at the minimum average cost, therefore we have

$$
A C^{I}\left(q_{I}^{* *}\right)=\frac{1}{q_{I}^{* *}} g\left(\frac{q_{I}^{* *}}{a}\right)=M C^{I}\left(q_{I}^{* *}\right)=\frac{1}{a} g^{\prime}\left(\frac{q_{I}^{* *}}{a}\right)
$$

When $q_{I}<q_{I}^{* *}$, the average cost of the upstream sector reduces as the quantity of immediate goods increases. This process is with increasing returns to scale. When $q_{I}>q_{I}^{* *}$, the average cost of the upstream sector increases as the quantity of immediate goods increases, which shows decreasing returns to scale.

The downstream sector's the minimum average cost is subject to an output level of $q_{F}^{* *}$, hence satisfying

$$
A C^{F}\left(q_{F}^{* *}\right)=\frac{g\left(q_{F}^{* *}\right)}{q_{F}^{* *}}=M C^{F}\left(q_{F}^{* *}\right)=g^{\prime}\left(q_{F}^{* *}\right)
$$

When $q_{F}<q_{F}^{* *}$, the average cost of the downstream sector reduces as the output of final goods increases, which satisfies the principle of increasing returns. When $q_{F}>q_{F}^{* *}$, the average cost of the downstream sector increases as the output of final goods increases, which demonstrates decreasing returns to scale.

From (6) and (7) we can get $q_{I}^{* * *}=a q_{F}^{* *}$. Therefore, we have

$$
A C^{I}\left(q_{I}^{* *}\right)=A C^{I}\left(a q_{F}^{* *}\right)=\frac{1}{a q_{F}^{* *}} g\left(q_{F}^{* *}\right)<A C^{F}\left(q_{F}^{* *}\right)=\frac{1}{q_{F}^{* *}} g\left(q_{F}^{* *}\right)
$$

which shows the minimum average cost of upstream sector is smaller than that of downstream sector. This conclusion holds under the assumption of $a>1$ which means different sectors have different production technology.

The vertically integrated firm's minimum average cost is subject to the output level of $q_{F}^{*}$, satisfying 
$A C^{V I}\left(q_{F}^{*}\right)=\frac{g\left(q_{F}^{*}\right)+g\left(\frac{q_{F}^{*}}{a}\right)}{q_{F}^{*}}=M C^{V I}\left(q_{F}^{*}\right)=g^{\prime}\left(q_{F}^{*}\right)+\frac{1}{a} g^{\prime}\left(\frac{q_{F}^{*}}{a}\right)$

When $q_{F}<q_{F}^{*}$, the average cost of the integrated firm reduces as the quantity of final goods increases. This process is with increasing returns to scale. When ${ }_{q_{F}}>q_{F}^{*}$, the average cost of the integrated firm increases as the quantity of final goods increases. This process holds the principle of decreasing returns.

When the quantity of final goods is $q \in\left(q_{F}^{* *}, q_{I}^{* *}\right)$, then the upstream sector is with increasing returns while the downstream sector is with decreasing returns. This is similar to what Stigler(1951) describes that one functional sector has decreasing-cost and the other has increasing-cost. It also satisfies Perry's (1989) arguments about specialization, namely economies of scales as well as diseconomies of scope across vertically related sectors. Vertical diseconomies of scope in our paper is reflected by downstream sector with decreasing returns when $\mathrm{w}_{q} q_{F}^{* *}$.

Vertically integrated firm is the price taker in the competitive market, maximizing its profit as follows,

$$
\max _{\left\{q_{F}\right\}} \pi^{V I}=p q_{F}-C^{V I}\left(q_{F}\right) \text { s.t. } \pi^{V I} \geq 0
$$

Then we get the inverse supply function of the integrated firm, which is the marginal cost curve where the price is higher than minimum average cost, as follows,

$p=M C^{V I}\left(q_{F}\right)=g^{\prime}\left(q_{F}\right)+\frac{1}{a} g^{\prime}\left(\frac{q_{F}}{a}\right), q_{F} \geq q_{F}^{*}$

The vertically integrated firm's supply firm could be rewritten as the following,

$q_{F}^{V I s}=q_{F}^{V l s}(p), \quad p \geq p_{F}^{*}=M C^{V I}\left(q_{F}^{*}\right)$

where $q_{F}^{V I s}(\cdot)$ is the inverse function of $M C^{V I}(\cdot)$. Since $M C^{V I}(\cdot)$ is a monotone function defined on $\left[q_{F}^{*},+\infty\right], M C^{V I}(\cdot)$

exists the inverse function of $q_{F}^{V I s}(\cdot)$ defined on $\left[p_{F}^{*},+\infty\right]$.

Suppose there are $n$ identical integrated firms in an industry, and $n$ is an integer larger than zero. Then the aggregate supply curve of the entire industry is presented as $Q_{F}^{V I s}=n q_{F}^{V I s}(p)$, where $p \geq p_{F}^{*}=M C^{V I}\left(q_{F}^{*}\right)$.

Under the principle of market clearing as $Q_{F}^{V I s}=n q_{F}^{V I s}(p)=Q_{F}^{d}(p, e)$ and $p \geq p_{F}^{*}=M C^{V I}\left(q_{F}^{*}\right)$, we develop the market free-entry equilibrium satisfying the following conditions:

$(n+1) q_{F}^{V I s}(p) \neq Q_{F}^{d}(p, e), \forall p>0$, or $(n+1) q_{F}^{V I s}(p)>Q_{F}^{d}(p, e), p \geq p_{F}^{*}$

From the above, we know that the number of firms $n$ in that industry is an equilibrium point. When the number of the firms is less than $n$, attracted by high profit, new firm will enter while if the number of the firms is larger than $n$, we have no such a price for a market clearing. Therefore, the equilibrium price, quantity of final goods, quantity of intermediate goods and the number of the integrated firms are presented by $\left(\bar{p}, \bar{q}_{F}, \bar{q}_{I}, \bar{n}\right)$, satisfying marketing clearing requirements and market free-entry conditions shown in (13). At equilibrium, integrated firm might gain profit, for 
potential newcomers can foresee negative profit in case of entry.

\subsection{Vertical disintegration}

Vertical disintegration refers that the upstream sector will separate from the integrated firm and become an independent upstream firm producing the intermediate goods, and the original firm will become the downstream firm producing the final goods.

We define the production function and the cost function of the upstream firm are

$q_{I}=a f\left(x_{I}\right), \quad a>1$

$C^{I}\left(q_{I}\right)=x_{I}=g\left(\frac{q_{I}}{a}\right)$

The production function of the downstream firm is

$q_{F}=\min \left\{f\left(x_{F}\right), q_{I}\right\}$

The downstream firm tries to minimize it cost subject to the output level of no less than ${ }_{F}$, that is

$\min _{x_{1}, x_{2}} C^{V D}\left(q_{F}\right)=x_{F}+p_{I} q_{I}$ s.t.min $\left\{f\left(x_{F}\right), q_{I}\right\} \geq q_{F}$

where $p_{I}$ is the market price of the intermediate goods. Solving for (17), we get the cost function of the downstream firm as follows,

$C^{V D}\left(q_{F}\right)=C^{F}\left(q_{F}\right)+p_{I} q_{F}=g\left(q_{F}\right)+p_{I} q_{F}$

We can derive the average cost and marginal cost of the downstream firm from (18) as follows.

$$
\begin{aligned}
& A C^{V D}\left(q_{F}\right)=A C^{F}\left(q_{F}\right)+p_{I}=\frac{g\left(q_{F}\right)}{q_{F}}+p_{I} \\
& M C^{V D}\left(q_{F}\right)=M C^{F}\left(q_{F}\right)+p_{I}=g^{\prime}\left(q_{F}\right)+p_{I}
\end{aligned}
$$

Since both the upstream and downstream firms are price takers and can freely enter the market, downstream firm maximizes the profit as the following.

$$
\max _{\left\{q_{F}\right\}} \pi^{V D}=p q_{F}-C^{V D}\left(q_{F}\right) \text { s.t. } \pi^{V D} \geq 0 .
$$

Take (18) into (21) and solve for it, then we obtain the inverse supply function of the disintegrated downstream firm,

$$
p=M C^{V D}\left(q_{F}\right)=M C^{F}\left(q_{F}\right)+p_{I}=g^{\prime}\left(q_{F}\right)+p_{I}, q_{F} \geq q_{F}^{* *}
$$

Consequently, the supply curve of the downstream firms is

$$
q_{F}^{V D s}=q_{F}^{V D s}\left(p-p_{I}\right), \quad p \geq p_{F}^{* *}=M C^{F}\left(q_{F}^{* *}\right)+p_{I}
$$

where $q_{F}^{V D s}(\cdot)$ is the inverse function of $M C^{F}(\cdot)$.

Simultaneously, the demand function of the intermediate goods for the downstream firms is

$$
q_{I}^{d}=q_{F}^{V D s}\left(p-p_{I}\right), \quad p \geq p_{F}^{* *}=M C^{F}\left(q_{F}^{* *}\right)+p_{I}
$$

If the number of downstream firms is $n$, then the aggregate supply function of the downstream industry is 
$Q_{F}^{V D s}=n q_{F}^{V D s}\left(p-p_{I}\right), \quad p \geq p_{F}^{* *}=M C^{F}\left(q_{F}^{* *}\right)+p_{I}$

The aggregate demand function of the intermediate goods for the downstream industry is

$Q_{I}^{d}=n q_{I}^{d}=n q_{F}^{V D s}\left(p-p_{I}\right), \quad p \geq p_{F}^{* *}=M C^{F}\left(q_{F}^{* *}\right)+p_{I}$

An upstream firm maximizes the profit as follows.

$$
\max _{\left\{q_{I}\right\}} \pi^{I}=p_{I} q_{I}-C^{I}\left(q_{I}\right) \text { s.t. } \pi^{I} \geq 0
$$

Take (15) into (27) and solve for it, hence we obtain the inverse supply function of the upstream firm as follows.

$p_{I}=M C^{I}\left(q_{I}\right)=\frac{1}{a} g^{\prime}\left(\frac{q_{I}}{a}\right), \quad q_{I} \geq q_{I}^{* *}$

The supply function of the upstream firm is

$q_{I}^{s}=q_{I}^{s}\left(p_{I}\right), \quad p_{I} \geq p_{I}^{* *}=M C^{I}\left(q_{I}^{* *}\right)$

where $q_{I}^{s}(\cdot)$ is the inverse function of $M C^{I}(\cdot)$.

Suppose that the number of identical firms is $m$ in the upstream industry, and $m$ is an integer larger than zero, then the aggregate supply function of the entire upstream industry is

$Q_{I}^{s}=m q_{I}^{s}\left(p_{I}\right), \quad p_{I} \geq p_{I}^{* *}=M C^{I}\left(q_{I}^{* *}\right)$

Market clearing in both the downstream and upstream industries satisfies the conditions respectively:

$Q_{F}^{V D s}=n q_{F}^{V D s}\left(p-p_{I}\right)=Q_{F}^{d}(p, e), \quad p \geq p_{F}^{* *}=M C^{F}\left(q_{F}^{* *}\right)+p_{I}$

$Q_{I}^{s}=m q_{I}^{s}\left(p_{I}\right)=Q_{I}^{d}=n q_{F}^{V D s}\left(p-p_{I}\right), \quad p_{I} \geq p_{I}^{* *}=M C^{I}\left(q_{I}^{* *}\right)$

The downstream firms' market free-entry equilibrium satisfies

$(n+1) q_{F}^{V D s}\left(p-p_{I}\right) \neq Q_{F}^{d}(p, e), \forall p>0$, or

$(n+1) q_{F}^{V D s}(p)>Q_{F}^{d}(p, e), p \geq p_{F}^{* *}=M C^{F}\left(q_{F}^{* *}\right)+p_{I}$

The upstream firms' market free-entry equilibrium satisfies

$(m+1) q_{I}^{s}\left(p_{I}\right) \neq n q_{F}^{V D s}\left(p-p_{I}\right), \forall p_{I}$, or

$(m+1) q_{I}^{s}\left(p_{I}\right)>n q_{F}^{V D s}\left(p-p_{I}\right), p_{I} \geq p_{I}^{* *}=M C^{I}\left(q_{I}^{* *}\right)$

Therefore, the equilibrium prices and quantities of the final goods and intermediate goods as well as the equilibrium number of the upstream and downstream firms are presented by $\left(\tilde{p}, \tilde{p}_{I}, \tilde{q}_{F}, \tilde{q}_{I}, \tilde{m}, \tilde{n}\right)$ respectively, satisfying marketing clearing requirements and market free-entry conditions of both upstream and downstream firms. Here we develop the exact nature of the free entry equilibrium in the case of vertical disintegration, i.e. the equilibrium prices and quantities 
of the final goods and intermediate goods as well as the equilibrium number of the upstream and downstream firms, resolving the second problem of Stigler's study questioned by Perry (1989). In addition, similar to the case of vertical integration, at the equilibrium point, both upstream and downstream firms might gain profit, for potential newcomers can foresee negative profit in case of entry.

\subsection{Conditions of Vertical integration and disintegration}

The difference between vertical integration and disintegration depends on whether intermediate goods are allocated via the market or within the firm. As we have assumed previously, as long as we can use competitive market, we will not use firm to allocate the resources. That is to say, in the case of vertical disintegration, if there are no prices of the

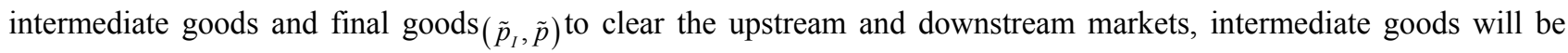
allocated within the firm, which is also the condition of vertical integration.

Combining the market clearing conditions of the downstream and upstream industry shown in (31) and (32) in the case of vertical disintegration, we develop the following expression:

$$
m q_{I}^{s}\left(p_{I}\right)=n q_{F}^{V D s}\left(p-p_{I}\right)=Q_{F}^{d}(p, e)
$$

$p \geq p_{F}^{* *}=M C^{F}\left(q_{F}^{* *}\right)+p_{I}$,

$p_{I} \geq p_{I}^{* *}=M C^{I}\left(q_{I}^{* *}\right)$

Let $p^{*}=M C^{F}\left(q_{F}^{* *}\right)+p_{I}^{* *}=M C^{F}\left(q_{F}^{* *}\right)+M C^{I}\left(q_{I}^{* *}\right)$, which means both prices of the intermediate goods and final goods are equal to their minimum average cost. Obviously when $Q_{F}^{d}\left(p^{*}, e\right)<q_{I}^{s}\left(p_{I}^{* *}\right)=q_{I}^{* *}$, we do not have an equilibrium within a framework of perfect competition. In other words, when the prices equal the minimum average costs and the extent of market $e$ is small enough, the aggregate demand of the final goods $Q_{F}^{d}\left(p^{*}, e\right)$ is below the minimum amount needed for the vertical disintegration, $q_{I}^{* *}$. Consequently, the upstream sector and downstream sector will produce in one integrated firm.

On the contrary, when $Q_{F}^{d}\left(p^{*}, e\right) \geq q_{I}^{* *}$, we can develop equilibrium of vertical disintegration within a framework of perfect competition. In other words, when the prices equal the minimum average costs and the extent of market $e$ is large enough, the aggregate demand of the final goods $Q_{F}^{d}\left(p^{*}, e\right)$ is above the minimum amount needed for the vertical disintegration, $q_{I}^{* *}$. Consequently, the upstream sector will separate from the integrated firm and become an independent upstream firm, vertical disintegration taking place.

Since we have proved the market clearing conditions as $Q_{F}^{V / s}=n q_{F}^{V I s}(p)=Q_{F}^{d}(p, e)$ and $p \geq p_{F}^{*}=M C^{V I}\left(q_{F}^{*}\right)$, when $Q_{F}^{d}\left(p_{F}^{*}, e\right)<q_{F}^{V I s}\left(p_{F}^{*}\right)=q_{F}^{*}$, there is no market equilibrium. When the prices equal the minimum average costs and the extent of market $e$ is too small, the aggregate demand of the final goods $Q_{F}^{d}\left(p_{F}^{*}, e\right)$ will be smaller than the break 
point $q_{F}^{*}$ at which the integrated firm prefers to shutdown. Therefore, the integrated firm will only produce when $Q_{F}^{d}\left(p_{F}^{*}, e\right) \geq q_{F}^{*}$.

Summing up, if we define the division of labor and specialization as vertical disintegration, then we can prove Smith theorem within a perfect competition framework.

SMITH THEOREM. Given the production functions of (2), (3), and the aggregate demand function of the industry (1), when the extent of market $e$ is small enough to make $Q_{F}^{d}\left(p_{F}^{*}, e\right) \geq q_{F}^{*}$ and $Q_{F}^{d}\left(p^{*}, e\right)<q_{I}^{* *}$ hold, intermediate goods will be produced within the vertically integrated firm. However, when the extent of market $e$ is so large that $Q_{F}^{d}\left(p^{*}, e\right) \geq q_{I}^{* *}$ holds, upstream sector will depart from the original firm, leading to vertical disintegration. In one word, the division of labor and specialization (or vertical disintegration) is limited by the extent of market.

Additionally, through a simple analysis, we can get another proposition from our theoretical model.

PROPOSITION 1. Given the production functions of (2), (3), and the aggregate demand function of the industry (1), the greater is the technical difference between intermediate goods and final goods $a$, the greater extent of market $\boldsymbol{e}$ is required for specialization (vertical disintegration). On the contrary, the smaller is the technical difference between intermediate goods and final goods $a$, the smaller extent of market $e$ is needed for specialization (vertical disintegration).

Proof. According to the Smith theorem, the condition of specialization (or vertical disintegration) is $Q_{F}^{d}\left(p^{*}, e\right) \geq q_{I}^{* *}$.

Taking $q_{I}^{* *}=a q_{F}^{* *} \quad$ into the above inequality, we obtain, $Q_{F}^{d}\left(p^{*}, e\right) \geq a q_{F}^{* *}$, where $q_{F}^{* *}$ satisfies $(7)$, namely, $g\left(q_{F}^{* *}\right)=q_{F}^{* *} g^{\prime}\left(q_{F}^{* *}\right)$. Since the industry's aggregate demand is the increasing function of $e$, with a larger $a$, we need a greater $e$ to take vertical disintegration. QED

This proposition illustrates that vertical disintegration not only depends on $e$, the extent of the market, but also $a$, the technical difference between the upstream and downstream sectors. The greater is the technical difference among different functional sectors, the more difficult it is to take vertical disintegration. On the contrary, the smaller is the technical difference, the more likely we make vertical disintegration.

\section{Conclusion}

Based on Stigler's (1951) conjecture, through a theoretical model, this article reproves the Smith theorem (the division of labor is limited by the extent of the market), via a framework of perfect competitive market, therefore resolving the Smith dilemma. Meanwhile, we develop the exact nature of equilibriums in the case of vertical integration and disintegration respectively, i.e. the equilibrium quantities and prices of the intermediate and final goods as well as the equilibrium number of the firms in an industry, solving the problems questioned by Perry (1989). Additionally, our finding also shows that the different technology levels in different production sectors will also hamper the specialization (or vertical disintegration) of the industry.

We follow Stigler's (1951) study, considering Smith theorem as the fundamental principle of industrial organization. Consequently, we can apply Smith theorem to solve the potential issues (1) related to vertical integration and disintegration (2) related to the division of labor and specialization (3) related to the study of economic growth and fluctuation.

Our limitation is that we do not take the transaction costs explicitly (Note 8) into the analysis process, but only choose two alternative mechanisms allocating resources, namely the firm and market, to analyze the problem, though we admit that transaction cost is a very important factor to determine the case of vertical integration and disintegration. Finally, 
our definition of the firm is too simplistic.

\section{Acknowledgements}

We are especially grateful to Lin Zhou for insightful comments. We would also like to thank Ning Sun, Ping Li, Xianfeng Huang, and seminar audiences at Liaoning University and Shanghai Jiao Tong University for helpful discussions.

\section{References}

Arora, A., Vogt, W.B., \& Yoon, J.W. (2009). Is the Division of Labor Limited by the Extent of the Market?: Evidence from the Chemical Industry. Industrial and Corporate Change, 18(5), 785-806. http://dx.doi.org/10.1093/icc/dtp013

Baumgardner, J. R. (1988). The division of labor, local markets, and worker organization. Journal of Political Economy, 96, 509-527. http://dx.doi.org/10.1086/261549

Becker, G. S., \& Murphy, K. M. (1992). The division of labor, coordination costs, and knowledge. Quarterly Journal of Economics, 107, 1137-1160. http://dx.doi.org/10.2307/2118383

Bresnahan, T., \& Gambardella, A. (1998). The division of inventive labor and the extent of the market, in E. Helpman (eds). General Purpose Technologies and Economic Growth. Cambridge MA: MIT Press.

Chen, Y. (2005). Vertical Disintegration. Journal of Economics \& Management Strategy, 14(1), 209-29. http://dx.doi.org/10.1111/j.1430-9134.2005.00040.x

Ciliberto, F., \& Panzar, J. (2011). Outsourcing and Vertical Integration in a Competitive Industry. Southern Economic Journal, 77(4), 885-900.

Coase, R. H. (1937). The nature of the firm, Economica, 386-405. http://dx.doi.org/10.1111/j.1468-0335.1937.tb00002.x

Desyllas, P. (2009). Improving Performance through Vertical Disintegration: Evidence from Uk Manufacturing Firms. Managerial and Decision Economics, 30(5), 307-24. http://dx.doi.org/10.1002/mde.1452

Dixit, A. K., \& Stiglitz, J. E. (1977). Monopolistic competition and optimum product diversity. American Economic Review, 67, 297-308.

Dufeu, I. (2004). Market size and vertical equilibrium in the context of successive Cournot oligopolies.Topics in Theoretical Economics, 4, 11-22. http://dx.doi.org/10.2202/1534-598X.1122

Duranton, G.., \& Jayet, H. (2011). Is the Division of Labour Limited by the Extent of the Market? Evidence from French Cities. Journal of Urban Economics, 69(1), 56-71. http://dx.doi.org/10.1016/j.jue.2010.08.004

Elberfeld, W. (2002). Market size and vertical integration: Stigler's hypothesis reconsidered. Journal of Industrial Economics, 50, 23-42. http://dx.doi.org/10.1111/1467-6451.00166

Grossman, S. J., \& Har, O. D. (1986). The costs and benefits of ownership: A theory of vertical and lateral integration. Journal of Political Economy, 94, 691-719. http://dx.doi.org/10.1086/261404

Hart, O. D., \& Holmstrom, B. (2010). A Theory of Firm Scope. Quarterly Journal of Economics, 125, 483-513. http://dx.doi.org/10.1162/qjec.2010.125.2.483

Hart, O. D., \& Moore, J. (1990). Property Rights and the Nature of the Firm. Journal of political economy, 98, 1119-1158. http://dx.doi.org/10.1086/261729

Heal, G. M. ed. (1999). The Economics of Increasing Returns. Cheltenham, UK and Northampton, MA: Edward Elgar.

Klein, B., Crawford, R., \& Alchian, A. (1978). Vertical integration, appropriable rents, and the competitive contracting process. Journal of Law and Economics, 21(2), 297-326. http://dx.doi.org/10.1086/466922

Li, B., \& Lu, Y. (2009). Geographic Concentration and Vertical Disintegration: Evidence from China. Journal of Urban Economics, 65(3), 294-304. http://dx.doi.org/10.1016/j.jue.2009.01.001

Locay, L. (1990). Economic development and the division of production between households and markets. Journal of political economy, 98, 965-982. http://dx.doi.org/10.1086/261715

Malerba, F., Nelson, R., Orsenigo, L., \& Winter, S. (2008). Vertical Integration and Disintegration of Computer Firms: A History-Friendly Model of the Coevolution of the Computer and Semiconductor Industries. Industrial and Corporate Change, 17(2), 197-231. http://dx.doi.org/10.1093/icc/dtn001 
Marshall, A. (1920). Principles of economics. London: McMillan.

Mill, John S. (1848). Principles of Political Economy. Torono: University of Torono Press.

Ng, Yew-Kwang, \& Zhang, D. (2003). The Smith dilemma: towards a resolution. [Online] Available: http://arrow.monash.edu.au/hdl/1959.1/2239

Nor, N.G. M., Abdullah, A.Z., \& Nor, K. M. (2006). Vertical Integration, Foreign Multinationals and Stigler's Hypotheses: An Empirical Test Using Malaysian Data. Asian Economic Journal, 20(3), 257-74. http://dx.doi.org/10.1111/j.1467-8381.2006.00235.x

Perry, M. K. (1989). Vertical integration: determinants and effects, in R. Schmalensee \& R.D.Willig (eds). Handbook of industrial organization,Volume I. Amsterdam: North Holland (Chapter 4). http://dx.doi.org/10.1016/S1573-448X(89)01007-1

Perry, M. K., \& Groff, R. H. (1988). Vertical integration and industry growth, Bell Laboratory Discussion Paper.

Ricardo, D. (1817)[1951]. On the Principles of Political Economy and Taxation. Cambridge, UK: Cambridge University Press.

Salinger, M. A. (1988). Vertical mergers and market foreclosure. Quarterly Journal of Economics, 103, 345-356. http://dx.doi.org/10.2307/1885117

Senior, N. W. (1836). An outline of the science of political economy. London: Clowes and Sons.

Smith, A. (1776)[1976]. An Inquiry into the Nature and Causes of the Wealth of Nations. Chicago: University of Chicago Press.

Stigler, G. J. (1951). The Division of Labor is Limited by the Extent of the Market. Journal of Political Economy, 59, 185-193. http://dx.doi.org/10.1086/257075

Williamson, O. E. (1975). Markets and hierarchies: analysis and antitrust implications. New York: Free Press.

Williamson, O. E. (1985). The Economic Institutions of Capitalism: Firms, Markets, Relational Contracting. New York: Free Press.

Yang, X., \& Borland, J. (1991). A microeconomic mechanism for economic growth, Journal of political economy, 99, 460-482. http://dx.doi.org/10.1086/261762

Yang, X., \& Ng, S. (1998). Specialization and Division of Labour: A Survey. in K. Arrow, Y-K Ng, and Xiaokai Yang (eds). Increasing returns and economic analysis. UK: Palgrave Macmillan.

Young, A. A. (1928). Increasing returns and economic progress. Economic Journal, 38, 527-542. http://dx.doi.org/10.2307/2224097

Zhou, H. (2004). The Division of Labor and the Extent of the Market. Economic Theory, 24, 195-209. http://dx.doi.org/10.1007/s00199-003-0415-y

\section{Notes}

Note 1. Here we assume that the functional sector with increasing returns is the upstream sector producing intermediate goods.

Note 2. Of course, we also need to include the equilibrium quantity produced by the newly specialized firm, although Perry (1989) does not explicitly mention it.

Note 3. One significant distinction between the study of Dixit and Stiglitz (1977) and that of Stigler (1951) is that the former analyze from the aspect of horizontal specialization and the latter focuses on vertical specialization.

Note 4. Circumventing the Smith dilemma means that the decision of specialization is not based on the marginal cost pricing within a framework of perfect competitive market.

Note 5. Particularly, Yang (1991) studies the specialization of the individuals, however, in this paper, we focus on the division of labor and specialization of the firm and industry. See Yang and $\mathrm{Ng}$ (1998).

Note 6. Stigler (1951) summarizes, failure of the price mechanism is the most important among other factors in the study of vertical integration or firm boundary, however, After Coase (1937), many representative economists like Willianmson (1975, 1985), Klein, Crawford \& Alchian (1978), Grossman \& Hart(1986), Hart \& Moore(1990) and Hart \& Holmsrom (2010) ignore Smith Theorem. In this paper, we only concentrate on proving Smith Theorem, therefore not taking 
transaction costs into analytical framework, but that would be a new direction of research.

Note 7. We follow Coase's (1937) idea, viewing the firm and market as two mechanisms allocating resources.

Note 8 . The reason we say that the transaction cost is not "explicitly" mentioned in the analysis, is that when we define the firm as a resource allocation mechanism via order, we have simultaneously assumed the existence of transition cost in the firm.
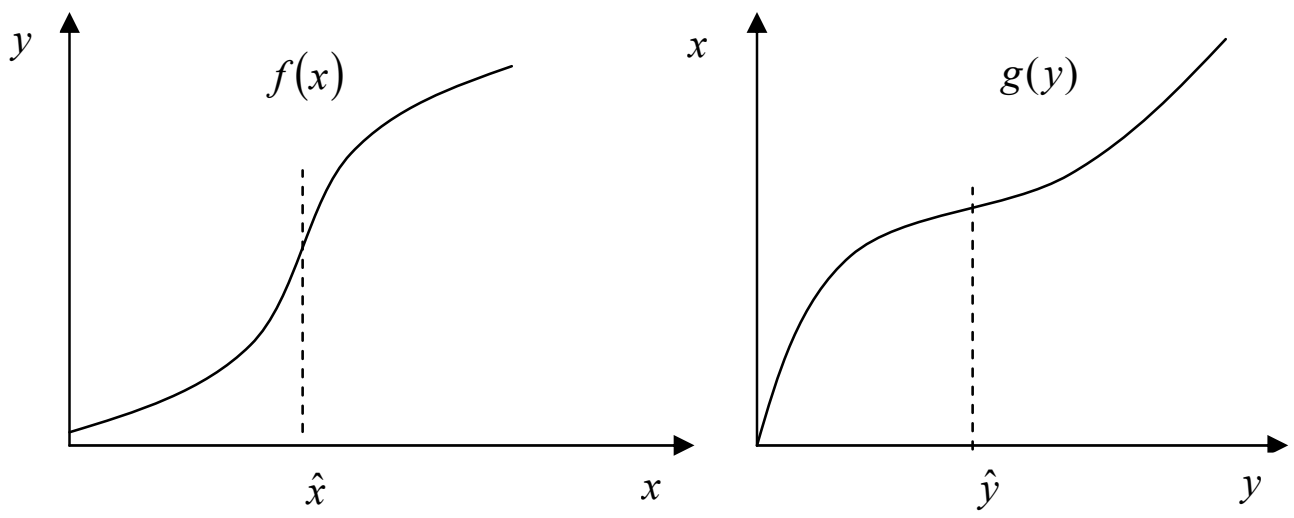

Figure 1. The curves of functions $f(x)$ and $g(y)$

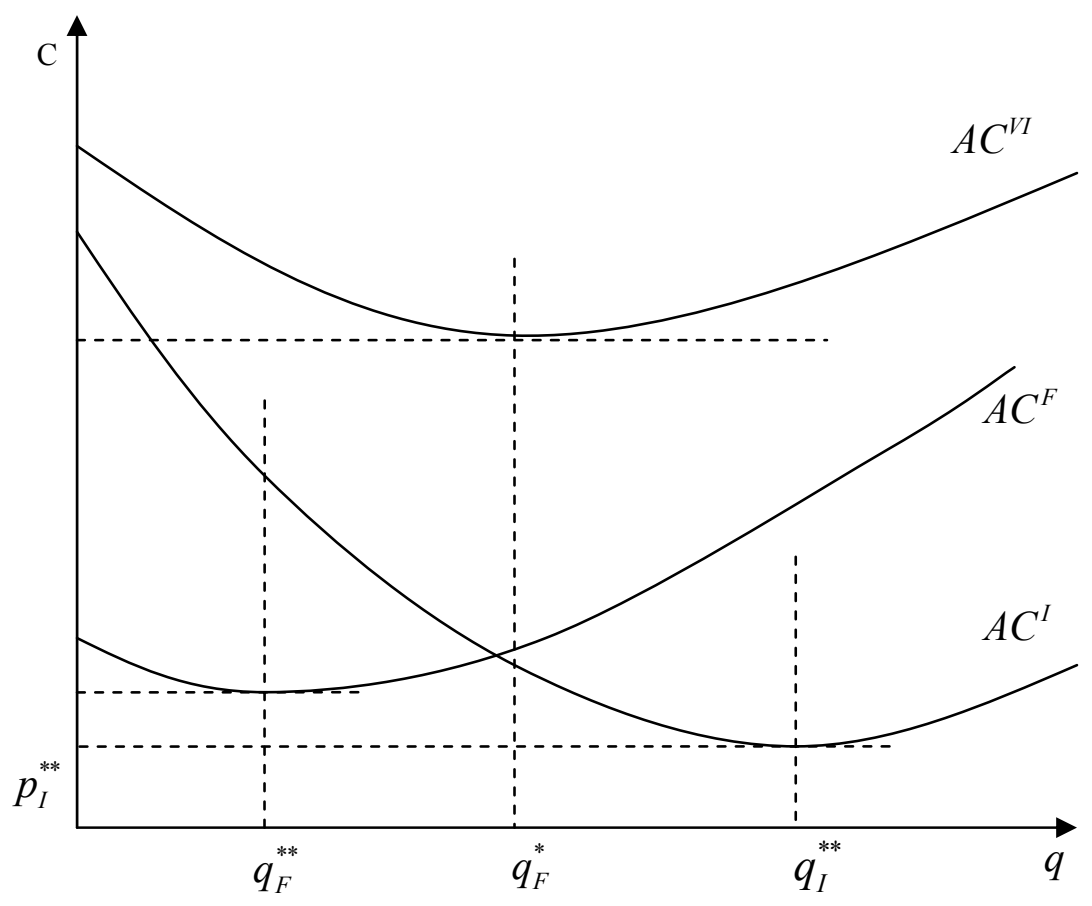

Figure 2. Average cost curves of the integrated firm and its functional sectors 


\section{Appendix}

From (5), we can derive the average cost and marginal cost function of the integrated firm,

$$
\begin{aligned}
& A C^{V I}\left(q_{F}\right)=\frac{g\left(q_{F}\right)+g\left(\frac{q_{F}}{a}\right)}{q_{F}} \\
& M C^{V I}\left(q_{F}\right)=g^{\prime}\left(q_{F}\right)+\frac{1}{a} g^{\prime}\left(\frac{q_{F}}{a}\right)
\end{aligned}
$$

As we know $C^{I}\left(q_{I}\right)=x_{I}=g\left(\frac{q_{I}}{a}\right)$, we can develop the average cost and marginal cost functions of the upstream sector,

$A C^{I}\left(q_{I}\right)=\frac{1}{q_{I}} g\left(\frac{q_{I}}{a}\right)$

$M C^{I}\left(q_{I}\right)=\frac{1}{a} g^{\prime}\left(\frac{q_{I}}{a}\right)$

From $C^{F}\left(q_{F}\right)=x_{F}=g\left(q_{F}\right)$, we can derive the average cost and marginal cost function of the downstream sector as follows,

$$
\begin{aligned}
& A C^{F}\left(q_{F}\right)=\frac{g\left(q_{F}\right)}{q_{F}} \\
& \operatorname{MC}^{F}\left(q_{F}\right)=g^{\prime}\left(q_{F}\right)
\end{aligned}
$$

Then we can obtain

$$
\begin{aligned}
& C^{V I}(q)=C^{F}(q)+C^{I}(q) \\
& A C^{V I}(q)=A C^{F}(q)+A C^{l}(q) \\
& M C^{V I}(q)=M C^{F}(q)+M C^{I}(q)
\end{aligned}
$$

From $g(y) \equiv f^{-1}(y)$, we get $f(g(y))=y$, hence $f^{\prime}(x) \llbracket g^{\prime}(y)=1$, where $x=g(y)$. Therefore, we have $g^{\prime}(y)=\frac{1}{f^{\prime}(x)}$ and $g^{\prime \prime}(y)=-\frac{f^{\prime \prime}(x)}{\left[f^{\prime}(x)\right]^{2}}$.

Since $f^{\prime}(x)>0$, we have $g^{\prime}(y)>0$. Also when $x<\hat{x}$, we get $f^{\prime \prime}(x)>0$, while when $x>\hat{x}, f^{\prime \prime}(x)<0$. Consequently, when $y<\hat{y}$, we have $g^{\prime \prime}(y)<0$ and when $y>\hat{y}, g^{\prime \prime}(y)>0$, where $\hat{y}=f(\hat{x})$.

Based on (39), we calculate the partial derivative with respect to $q_{I}$,

$\frac{d M C^{I}\left(q_{I}\right)}{d q_{I}}=\frac{1}{a^{2}} g^{\prime \prime}\left(\frac{q_{I}}{a}\right)$

From $g(y) \equiv f^{-1}(y)$, we know that when $\frac{q_{I}}{a}<\hat{y}, \frac{d M C^{I}\left(q_{I}\right)}{d q_{I}}=\frac{1}{a^{2}} g^{\prime \prime}\left(\frac{q_{I}}{a}\right)<0$, which means the marginal cost of the upstream sector will decrease with an increase in $q_{I}$; when $\frac{q_{I}}{a}>\hat{y}, \frac{d M C^{I}\left(q_{I}\right)}{d q_{I}}=\frac{1}{a^{2}} g^{\prime \prime}\left(\frac{q_{I}}{a}\right)>0$, which means the marginal cost of the 
upstream sector will increase as $q_{I}$ increases. Therefore, the marginal cost curve of the upstream sector is U-shaped with its minimum point subject to the output level of $\hat{q}_{I}=a \hat{y}$.

Based on (41), we calculate the partial derivative with respect to $q_{F}$,

$\frac{d M C^{F}\left(q_{F}\right)}{d q_{F}}=g^{\prime \prime}\left(q_{F}\right)$

Also from $g(y) \equiv f^{-1}(y)$, we know that when $q_{F}<\hat{y}, \frac{d M C^{F}\left(q_{F}\right)}{d q_{F}}=g^{\prime \prime}\left(q_{F}\right)<0$, which means the marginal cost of the downstream sector will decrease with the output growth; when $q_{F}>\hat{y}, \frac{d M C^{F}\left(q_{F}\right)}{d q_{F}}=g^{\prime \prime}\left(q_{F}\right)<0$, which means the marginal cost of the downstream sector will increase as output expands. Therefore, the marginal cost curve of the downstream sector is also U-shaped with its minimum point subject to the output level of $\hat{q}_{F}=\hat{y}$.

Based on (44) $M C^{V I}(q)=M C^{F}(q)+M C^{I}(q)$, we calculate the partial derivative with respect to $q$,

$\frac{d M C^{V I}(q)}{d q}=\frac{d M C^{F}(q)}{d q}+\frac{d M C^{I}(q)}{d q}=g^{\prime \prime}(q)+\frac{1}{a^{2}} g^{\prime \prime}\left(\frac{q}{a}\right)$

When $q<\hat{y}$, and $\frac{q}{a}<\hat{y}$, we have $g^{\prime \prime}(q)<0, \frac{1}{a^{2}} g^{\prime \prime}\left(\frac{q}{a}\right)<0$, and hence $\frac{d M C^{V I}(q)}{d q}=g^{\prime \prime}(q)+\frac{1}{a^{2}} g^{\prime \prime}\left(\frac{q}{a}\right)<0$.

When $q>a \hat{y}$, and $q>\hat{y}$, we have $g^{\prime \prime}(q)>0, \frac{1}{a^{2}} g^{\prime \prime}\left(\frac{q}{a}\right)>0$, and hence $\frac{d M C^{V I}(q)}{d q}=g^{\prime \prime}(q)+\frac{1}{a^{2}} g^{\prime \prime}\left(\frac{q}{a}\right)>0$.

We assume that $\frac{d M C^{V I}(q)}{d q}$ is monotone continuous function, then there exists such $\hat{q}$ that lies in $\hat{y} \leq \hat{q} \leq a \hat{y}$ and satisfies $\frac{d M C^{V I}(\hat{q})}{d q}=g^{\prime \prime}(\hat{q})+\frac{1}{a^{2}} g^{\prime \prime}\left(\frac{\hat{q}}{a}\right)=0$.

When $q<\hat{q}, \frac{d M C^{V I}(q)}{d q}=g^{\prime \prime}(q)+\frac{1}{a^{2}} g^{\prime \prime}\left(\frac{q}{a}\right)<0$ and when $q>\hat{q}, \frac{d M C^{V I}(q)}{d q}=g^{\prime \prime}(q)+\frac{1}{a^{2}} g^{\prime \prime}\left(\frac{q}{a}\right)>0$. Therefore, the marginal cost curve of the integrated firm is also U-shaped with its minimum point subject to the output level of $\hat{q}$.

Due to the relations between marginal cost and average cost, we can also derive the U-shaped average cost curves of the integrated firm and its upstream and downstream sectors. 